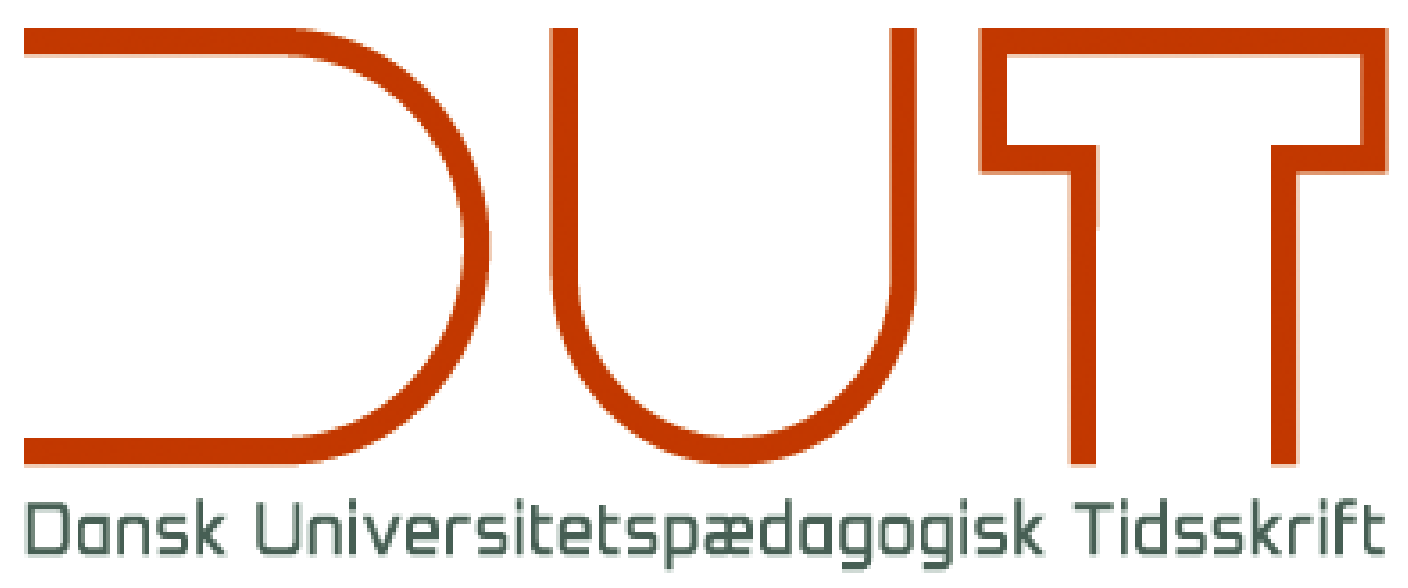

Læringsrum

Årgang 14 nr. 27 / 2019

Titel

DUT Guide: Peer-Feedback

Forfattere

Sidetal

Udgivet af

URL

Rikke von Müllen

$188-196$

Dansk Universitetspædagogisk Netværk, DUN

> http://dun-net.dk/

Betingelser for brug af denne artikel

(c) Copyright
Denne artikel er omfattet af ophavsretsloven, og der må citeres fra den. Følgende betingelser skal dog være opfyldt:

- Citatet skal være i overensstemmelse med "god skik"

- Der må kun citeres „i det omfang, som betinges af formålet“

- Ophavsmanden til teksten skal krediteres, og kilden skal angives ift. ovenstående bibliografiske oplysninger.

DUT og artiklens forfatter 


\title{
DUT Guide: Peer-Feedback
}

\author{
Rikke von Müllen"a,1 \\ apædagogisk Center Samfundsvidenskab, Københavns Universitet.
}

\begin{abstract}
Peer-feedback er et populært svar på flere forskellige udfordringer, de videregående uddannelser står overfor. Det er også en meget kompleks pædagogisk praksis med mange led, som på lige så mange måder kan kompromitteres med det resultat, at peer-feedback ikke fører til de læringsmål, der var intenderede. Denne artikel vil derfor give nogle både forskningsbaserede og praktisk afprøvede bud på, hvad de vigtigste principper er for den praktiske gennemførelse af peer-feedback.
\end{abstract}

\section{Baggrund}

Peer-feedback i videregående uddannelser besynges fra mange sider og af ret forskelligartede grunde.

Eric Mazur og alle de, der siden har udviklet 'peer-to-peer tutoring', argumenterer for, at de studerende bedre kan hjælpe hinanden med at lære, end eksperter kan, fordi de bedre forstår hinandens misforståelser (Mazur, 1997; Falchikov, 2001).

De, der er optagede af at styrke den forskningsbaserede undervisning, argumenterer for, at man med peer-feedback mellem studerende efterligner forskningsverdenens peer reviews og dermed bidrager til, at de studerende får den rette kritiske forståelse af vidensproduktionens natur (Horst, 2018; Schäfke et al., 2018).

I den universitetspædagogiske litteratur om peer-feedback er der desuden forskere, der underbygger, at de studerende er kvalificerede til at bedømme hinanden (Li et al., 2016), og mange andre der mener, at det er mindre vigtigt, om de studerende er kvalificerede til at bedømme hinanden, eller endda skadeligt at de gør det - det vigtige er, at de gennem produktionen af peer feedbacken lærer at selvevaluere (Nicol et al., 2014; Reinholz, 2016, Liu \& Carless 2006).

Endelig kunne man høre den tidligere Uddannelses- og Forskningsminister Tommy Ahlers nogle måneder efter sin tiltrædelse forklare Deadlines Sigge Winther, at de studerendes behov for mere feedback kunne løses omkostningsneutralt med peer-feedback (Deadline, DR2, 10. juni 2018).

Der er altså en vis konsensus på tværs af interesser om, at vel-designet peer-feedback er godt for universitetsstuderende.

Samtidig er der ikke entydigt gode erfaringer med implementering af peer-feedback. Ikke at peer-feedback derved adskiller sig fra andre pædagogiske tiltag; men også peer-feedback er følsomt overfor detaljerne i, hvordan det implementeres, og mange velmente forsøg er enten sandet til i praktiske udfordringer eller modstand fra de studerende, eller har i hvert fald ikke

\footnotetext{
${ }^{1}$ Kontakt: rvm@samf.ku.dk
} 
kunnet producere evidens for deres egen effekt'. Og som Panadero et al. $(2016$, s. 18) minder os om, er der mange bevægelige dele i implementering af peer-feedback:

(...) the available evidence suggests that it is of the utmost importance to clarify the rational for peer assessment in advance, involve students in determining the criteria, clearly specify the peer assessment format as well as how students are supposed to interact, and provide them with sufficient training and scaffolds to conduct the peer assessment activities.

Bare en simpel delmængde som "clarify the rational for peer assessment in advance" kræver ikke blot, at man ekspliciterer rationalet, men ofte også en indsats for, at de studerende hører, stoler på og husker, hvad underviser siger i den forbindelse. Så der kan være utallige forklaringer på, at gode intentioner og planer ikke kan omsættes i øjeblikkelig succes ved omstrukturering af undervisning. En god peer-feedback-kultur er noget, der skal skabes, ikke blot en enkelt aktivitet, der skal afvikles.

Denne artikel vil give nogle praktiske anvisninger til, hvordan peer-feedback bliver veldesignet.

'Peer-feedback'ii dækker en bred vifte af pædagogiske praksisser (Adachi et al., 2018; Gielenet al., 2011). Rådene her er rettet mod praksisser, hvor studerende alene eller i grupper har produceret faglige produkter eller gennemført faglige præstationer, som andre studerende giver fremadrettet, ikke-bedømmende (formativ) feedback på. Det handler altså her udelukkende om 'peer-feedback for læring' (Liu \& Carless 2006).

\section{Praksispunkter}

1. Forklar formålet med peer-feedback. Mange gange

2. Ekspliciter, diskuter og eksemplificer kriterier og målopfyldelse

3. Instruer og rammesæt peer-feedbackgivningen

4. Stikprøv feedbacken

5. Pres om nødvendigt bundniveauet af feedback opad

6. Faciliter selv-feedback

7. Støt modtagelse, vurdering og anvendelse af feedback

8. Lad genaflevering være et krav eller en mulighed

9. Nægt at implementere peer-feedback, hvis det ikke er muligt at gøre i hvert fald noget af ovenstående. 


\section{Tip 1}

\section{Forklar formålet med peer-feedback. Mange gange.}

Det dybeste læringsudbytte af peer-feedback kommer ikke af at modtage, men af at producere feedback (Nicol et al., 2014; Cho \& MacArthur, 2010; 2011). Det er kontraintuitivt for de fleste studerende, som ønsker sig feedback for at få rettelser eller alternative handlemuligheder og kun giver peer-feedback, fordi det er betingelsen for at modtage, og de opfatter måske endda peer-feedback som en spareøvelse. Og mange af de studerende, der oplever udbyttet af at give feedback, reflekterer ikke uden opfordring over dette udbytte (von Müllen et al., 2018, kap. 4; Nicol et al., 2014). Det kræver altså mere at overbevise studerende om peer-feedbacks læringspotentiale end, at ord derom forlader undervisers mund. Det kræver, at underviser er tålmodig, gentager formålet igen og igen, demonstrerer for de studerende, at de faktisk opnår det forventede udbytte, og designer muligheder for og øvelser i at reflektere over egen læring $f x$ ved at holde peer-feedbacken tilbage, indtil de studerende har reflekteret over deres udbytte af at være feedbackgivere. Og selv med hele denne indsats gives der stadig ingen garantier for, at vi kan få alle vores studerende til at aflære deres stærke forforståelser på dette felt (McLean et al., 2015; O'Donovan, 2017).

\section{Tip 2}

\section{Ekspliciter, diskuter og eksemplificer kriterier og målopfyldelse.}

I langt de fleste undervisningskontekster på universitetsniveau vil kriteriebaseret feedback være det ønskværdigeiii. Det er kun muligt at lave kriteriebaseret peer-feedback, hvis det lykkes at skabe en fælles forståelse af de faglige kriterier i hele studentergruppen (Nicol \& Macfarlane-Dick, 2006, s.206). Den første vanskelighed er, at underviseren eller undervisergruppen selv skal have et rimeligt klart og entydigt billede af, hvad kriterierne er. Den næste er, at faglige kriterier typisk er alt for komplekse til fyldestgørende at kunne formuleres i få og korte sætninger og dermed ikke kan deles med studerende alene ved at vise en slide eller udlevere en kriterieliste. Også i dette tilfælde kræver dyb læring af kompleks faglighed, at de studerende involveres aktivt. Det kan gøres med brug af eksempler på det produkt, de studerende skal producere, som de studerende fx starter med selv at forberede feedback på, hvorefter underviser enten selv leverer feedback på eksemplet og beder de studerende sammenligne deres egen feedback med undervisers, eller underviser forklarer kriterierne og beder de studerende forsøge at give feedback igen og se, om deres feedback bliver anderledes, når de tager udgangspunkt i kriterier (Carless \& Chan, 2017; Hawe et al., 2019).

Det er også en effektiv og velafprøvet praksis at lade de studerende studere gode eksempelprodukter (altid mere end ét (Carless \& Boud, 2018)) og i fællesskab formulere kriterier for genren, som underviser kan kvalificere og udfordre, til man ender med en fælles forståelse af kvalitet, allerhelst i form af en 'rubric', hvor kriterierne er specificeret i niveaueriv.

Selv med alverdens indledende øvelser er det en vanskelig opgave at levere god feedback. Lykkeligvis vil det at gennemgå en velfungerende peer review-proces i sig selv styrke og nuancere de studerendes kriterieforståelse til næste gang, så forløb med flere runder peerfeedback er at foretrække (McConlogue, 2015; Carless \& Boud, 2018). 


\section{Tip 3}

\section{Instruer og rammesæt peer-feedback-givningen.}

Kun en tåbe frygter ikke logistikken i peer-feedback! Klar og nedskrevet instruks er en nøgle til de fleste studenteraktiverende undervisningsformater, men intet sted er det vigtigere end i peer-feedback, at alle ved præcis, hvor meget der skal afleveres, hvornår, til hvem, hvordan, i hvilket format osv. Pilottest din instruks, alt skal være med, intet bør overlades til fantasien eller forhandling - selvom man naturligvis sagtens - og med fordel - kan forhandle rammerne med sine studerende, inden man skriver dem ned.

Bruger man online-systemer ${ }^{v}$ til at styre logistikken, bør de studerende gå hele processen igennem i undervisningen, så de studerende synkront får prøvet at logge ind og besvare et simpelt spørgsmål, give feedback på nogle andres svar, aflevere feedbacken og evt. give feedback på feedbacken, inden de slippes løs asynkront.

\section{Tip 4}

\section{Stikprøv feedbacken.}

For både underviser og studerende kan det være værdifuldt, at underviser gennemlæser stikprøver af feedbacken. For underviser kan det give adgang til nyttig information om de studerendes faglige niveau, som kan hjælpe underviser med at planlægge fremtidig undervisning præcist til de studerendes behov (Nicol \& Macfarlane-Dick, 2006). Stikprøver af peerfeedback kan også udgøre en kilde til løbende evaluering af fagligt udbytte, som er uafhængig af de studerendes tilfredshed.

Studerendes første og største anke mod peer-feedback er som regel, at feedbacken er ukvalificeret, hvilket fører til usikkerhed om, hvorvidt man nu kan stole på det, man får at vide af sine feedbackgivere (Kaufman \& Schunn, 2011). Usikkerhed er ubehageligt og fører ofte til modvilje mod peer-feedback blandt studerende. Det kan have en stor effekt på denne usikkerhed og modvilje, at underviser er til stede i processen i en eller anden form. Det kan ske ved, at underviser udtager stikprøver af de studerendes faglige produkter og tilbyder kollektiv feedback med udgangspunkt i stikprøverne. Det kan ske ved, at underviser giver feedback på et udsnit af feedbacken og på den måde er med til at kvalitetssikre niveauet. Det kan ske ved, at underviser udgør en anke-instans, hvor studerende, der er meget i tvivl om rigtigheden af den modtagne peer-feedback, kan få den efterprøvet. I et program som Peergrade.io kan det sidstnævnte gøres ved, at studerende kan sætte 'flag' ved feedback, som de synes, underviser skal kigge nærmere på. Ved mundtlig aflevering af peer-feedback kan underviser være til stede, gå rundt mellem de studerende, der udveksler feedback, lytte lidt, måske give sit besyv med, og på den måde reducere de studerendes frygt for, at peer-feedback kan løbe helt af sporet.

\section{Tip 5}

\section{Pres om nødvendigt bundniveauet af feedback opad.}

I nogle undervisningskontekster er der store grupper af studerende, der er mere optagede af at minimere deres arbejdsbyrde end af at maksimere deres læring. Det kan resultere i, at deres medstuderende modtager peer-feedback af unødvendigt ringe kvalitet. 
Det er derfor vigtigt for at minimere de studerendes usikkerhed eller modvilje mod peerfeedback at hæve bundniveauet af peer-feedbacken. Både tip 1, 2, 3 og de sidste forslag under tip 4 bidrager til det. Derudover bør man altid lade hver studerende eller gruppe få feedback fra flere medstuderende, så en eventuel ringe eller fejlagtig feedback aldrig står alene. Man kan også lade de studerende give feedback på feedbacken. Og i nogle kontekster kan det være fremmende for seriøsiteten at indføre deciderede kontrolinstanser. For eksempel som en underviser, der kontrollerede, hvor meget tid de studerende havde brugt i Peergrade og så meddelte holdet, at de, der havde brugt åbenlyst for lidt tid, fik en ekstra dag til at prøve igen, og derved markerede for hele holdet, at sjusk ikke blev tolereret (Nyboe Tabor \& von Müllen i review).

\section{Tip 6}

\section{Facilitér selv-feedback.}

At få adgang til både eksplicitte kriterier og medstuderendes eksempler og at engagere sig i kriteriebaseret analyse heraf giver mange studerende inspiration og kompetence til selvfeedback og revision af eget produkt. Nicol et al. (2014) ser, at flertallet af studerende i deres lille studie laver revisioner i deres eget produkt efter at have givet feedback til medstuderende, men inden de selv har modtaget feedback.

Der er uudnyttet potentiale i at hjælpe alle studerende til at blive opmærksomme på udbyttet af selv-feedback. Det kan gøres ved at systematisere det som et af trinnene i peer-feedbackprocessen, at de studerende skal producere selv-feedback mellem aflevering og modtagelse af peer-feedback; naturligvis støttet af forklaring og begrundelse fra underviser, som kan hjælpe de studerende med at blive bevidste om den opnåede (og livslangt nyttige) kompetence i selv-feedback.

\section{Tip 7}

\section{Støt modtagelse, vurdering og anvendelse af feedback.}

Det er ikke altid rart at få feedback, og overladt til sig selv vil nogle studerende undgå feedbacken eller læse/høre den meget kritisk eller reagere meget selvkritisk på den (Draper, 2009; Forsythe \& Johnson, 2017). Endnu flere vil bare ikke handle som konsekvens af feedbacken (Winstone et al., 2017).

Som underviser kan man facilitere en mere professionel eller systematisk modtagelse af peer-feedbacken (Carless \& Boud, 2018) fx ved at bede alle studerende udarbejde planer for, hvad de vil tage til sig fra feedbacken, og hvordan de vil omsætte det til ændringer i produktet. Og man kan forsøge at hjælpe de studerende i gang med selve den vanskelige revision $\mathrm{fx}$ ved at vise, hvordan eksempler på studenterprodukter kunne revideres på baggrund af bestemte feedback-kommentarer. Der kunne let tænkes andre metoder, men en opmærksomhed på, at kvalitetsrevision ikke automatisk følger af kvalitetsfeedback, er det centrale her. 


\section{Tip 8}

\section{Lad genaflevering være et krav eller en mulighed}

Feedbacks formål er at hjælpe studerende med at reducere uoverensstemmelsen mellem deres nuværende præstation og deres mål for præstationenvi.

Det er afgørende for motivationen for at tage imod peer-feedback (og anden feedback), at feedbacken er formativ, ikke bare af hensigt, men af funktion. Peer-feedbacken skal altså gives på et produkt, som skal eller kan genafleveres, så behovet for feedbacken er åbenlyst, og revisionen ikke kan udskydes (Jonsson, 2013). Først når de studerende har været igennem hele feedbackcirklen, og deres produkt er blevet forbedret, er læringspotentialet nået (Reinholz, 2016; Carless, 2019).

Det kan i nogle forløb være et vanskeligt punkt at leve op til, fordi det vil kræve større og måske omkostningsfyldte ændringer. Det kan fx være nødvendigt at skifte til en eksamensform som portfolio-eksamen, som måske er dyrere at gennemføre, end den hidtidige eksamensform; men muligheden for genaflevering er essentiel, og mange studerende reagerer prompte med mindre engagement eller decideret vægring, hvis peer-feedback kommer til at stå som en øvelse, der ikke har et klart formål og udbytte i form af forbedret (og bedømt) præstation (Carless et al., 2011).

\section{Tip 9}

\section{Nægt at implementere peer-feedback, hvis det ikke er muligt at gøre i hvert fald noget af ovenstående.}

Peer-feedback er en kompliceret didaktisk konstruktion med mange bevægelige dele, og mange muligheder for at kompromittere alignment, motivation eller læringspotentiale (Biggs \& Tang, 2011; Reinholz, 2016). Det er derfor rigeligt risikabelt at begive sig ud i uden at forbryde sig mod de grundlæggende principper, som er beskrevet i de første otte tips. Yd derfor modstand, når peer-feedback foreslås som et ressourcebesparende quick fix. Ved rettidigt at forebygge, at dine studerende efterlades med forudsigeligt dårlige oplevelser med peerfeedback, gør du det muligt for dine studerendes fremtidige undervisere at implementere vel-designet peer-feedback (og gruppearbejde og alle mulige andre implementeringsfølsomme pædagogiske tiltag) uden at blive mødt af en studentergrupper, der siger: "det har vi prøvet, det virker aldrig!"

\section{Konklusion}

Det er svært at finde universitetspædagogiske forskere, der grundlæggende er kritiske over for ideen om peer-feedback. Peer-feedback kan fremme adskillige af de overordnede mål, vi sigter mod i universitetsuddannelser: selvstændighed, internalisering af faglige kriterier, kritisk tænkning, selvevaluering, time-on-task, forskningsbaseret undervisning, og kan endda foregå asynkront online. Men utallige er også mulighederne for at lave design- eller implementeringsfejl, som gør, at velmente peer-feedback-initiativer i stedet genererer undvigelsesstrategier, skuffelse, frustration, socialt ubehag eller indsatsminimering. 
Hvis man følger de ni råd leveret her og omhyggeligt tilpasser dem sin egen undervisningskontekst, vil man kunne undgå de mest forudsigelige problemer og være godt på vej mod at implementere peer-feedback, der støtter de studerendes læring på vigtige områder.

\section{Referencer}

Adachi, C., Tai, J., \& Dawson, P. (2018). A framework for designing, implementing, communicating and researching peer assessment. Higher Education Research \& Development, 37:3, 453-467. https://doi.org/10.1080/07294360.2017.1405913

Andrade, H. G. (2005). Teaching with rubrics: The good, the bad, and the ugly. College teaching, 53(1), 27-31. doi: $10.1080 / 02602930902862859$

Biggs, J., Tang, C. (2011). Teaching for Quality Learning at University - What the Student Does (4th Ed.). UK: Open University Press.

Carless, D. (2019). Feedback loops and the longer-term: towardsfeedback spirals. Assessment \& Evaluation in Higher Education, 44:5, 705-714. doi:10.1080/02602938.2018.1531108

Carless, D., \& Boud, D. (2018). The development of student feedback literacy: enabling uptake of feedback. Assessment \& Evaluation in Higher Education, 43:8, 1315-1325. https://doi.org/10.1080/02602938.2018.1463354

Carless, D., \& Chan, K.K.H. (2017). Managing dialogic use of exemplars. Assessment \& Evaluation in Higher Education, 42:6, 930-941. doi:10.1080/02602938.2016.1211246

Carless, D., Salter, D., Yang, M., \& Lam, Y. (2011). Developing sustainable feedback practices. Studies in Higher Education, 36:4, 395-407. doi:10.1080/03075071003642449

Cho, K., \& MacArthur, C. (2010). Student revision with peer and expert reviewing. Learning and instruction, 20:4, 328-338. doi:https://doi.org/10.1016/j.learninstruc.2009.08.006.

Cho, K., \& MacArthur, C. (2011). Learning by reviewing. Journal of Educational Psychology, 103:1, 73-84. doi: http://dx.doi.org/10.1037/a0021950.

Draper, S. W. (2009). What are learners actually regulating when given feedback?. British Journal of Educational Technology, 40, 306 - 315. doi:10.1111/j.1467- 8535.2008.00930.x

Elbow, P. (1981). Writing with Power. New York: Oxford University Press.

Falchikov, N. (2001). Learning together: Peer tutoring in higher education. London: Routledge.

Forsythe, A., \& Johnson, S. (2017). Thanks, but no-thanks for the feedback. Assessment \& Evaluation in Higher Education, 42:6, 850-859. DOI:10.1080/02602938.2016.1202190

Gielen,S., Dochy, P., \& Onghena, P. (2011). An inventory of peer assessment diversity. Assessment \& Evaluation in Higher Education, 36:2, 137-155, doi:10.1080/02602930903221444

Hattie, J., Timperley, H. (2007). The Power of Feedback. Review of Educational Research, 77:1, 81-112. https://doi.org/10.3102/003465430298487 
Hawe, E., Lightfoot, U., \& Dixon, H. (2019). First-year students working with exemplars: promoting self-efficacy, self-monitoring and self-regulation. Journal of Further and Higher Education, 43:1, 30-44. https://doi.org/10.1080/0309877X.2017.1349894

Horst, S. (2018). Tidsskrift for studerendes forskningspublikationer. I: Damsholt, T., Jensen, H.N., Rump, C.Ø. (2018). Videnskabelse på Universitetet.Samfundslitteratur.

Jonsson, A. (2013). Facilitating productive use of feedback in higher education. Active Learning in Higher Education, 14:1, 63-76. https://doi.org/10.1177/1469787412467125

Kaufman, J. H., \& Schunn, C. D. (2011). Students' perceptions about peer assessment for writing: their origin and impact on revision work. Instructional Science, 39:3, 387-406. https://doi.org/10.1007/s11251-010-9133-6

Li, H., Xiong, Y., Zang, X., Kornhaber, M.L., Lyu, Y., Chung, K.S. \& Suen, H.K. (2016). Peer assessment in the digital age: a meta-analysis comparing peer and teacher ratings. Assessment \& Evaluation in Higher Education, 41:2, 245-264. doi: 10.1080/02602938.2014.999746

Ngar-Fun Liu \& David Carless (2006). Peer feedback: the learning element of peer assessment, Teaching in Higher Education, 11:3, 279290, DOI: $\underline{10.1080 / 13562510600680582}$

Mazur, E. (1997). Peer instruction: A user's manual. Upper Saddle River, N.J.: Prentice Hall.

McConlogue, T. (2015). Making judgements: investigating the process of composing and receiving peer feedback. Studies in Higher Education, 40:9, 1495-1506. DOI:10.1080/03075079.2013.868878

McLean, A., Bond, C., \& Nicholson, H. (2015). An Anatomy of Feedback: A Phenomenographic Investigation of Undergraduate Students' Conceptions of Feedback. Studies in Higher Education, 40:5, 921-932. Doi:10.1080/03075079.2013.855718.

Nicol, D., Macfarlane-Dick, D. (2006). Formative Assessment and Self-Regulated Learning: A Model and Seven Principles of Good Feedback Practice. Studies in Higher Education, 31:2, 199-218. doi: 10.1080/03075070600572090

Nicol, D., Thomson, A., Breslin, C. (2014). Rethinking Feedback Practices in Higher Education: A Peer Review Perspective. Assessment \& Evaluation in Higher Education, 39:1, 102- 122. doi: http://dx.doi.org/10.1080/02602938.2013.795518

O'Donovan, B. (2017). How Student Beliefs about Knowledge and Knowing Influence Their Satisfaction with Assessment and Feedback. Higher Education, 74, 617-633. doi: 10.1007/s10734-016-0068-y

Panadero, E., Jonsson, A., Strijbos JW. (2016) Scaffolding Self-Regulated Learning Through Self Assessment and Peer Assessment: Guidelines for Classroom Implementation. In Laveault D., Allal L. (eds). Assessment for Learning: Meeting the Challenge of Implementation. The Enabling Power of Assessment, vol 4. Springer International Publishing.

Race, P. (2013). The lecturer's toolkit: a practical guide to assessment, learning and teaching.London: Routhledge.

Reddy, Y. M. and H. Andrade (2010). A review of rubric use in higher education. Assessment \& 
Evaluation in Higher Education 35(4): 435-448. doi.org/10.3200/CTCH.53.1.27-31

Reinholz, D. L. (2016). The assessment cycle: a model for learning through peer assessment. Assessment \& Evaluation in Higher Education, 41:2, 301-315. https://doi.org/10.1080/02602938.2015.1008982

Schäfke, W., Kristiansen, B., Elgaard, K. K. E., \& Hølmkjær, M. S. (2018). Forskningsbaseret læring og innovativ praksis på jurauddannelsen. Dansk Universitetspœedagogisk Tidsskrift, 13:24, 104-119.

Schneider, M., \& Preckel, F. (2017). Variables associated with achievement in higher education: A systematic review of meta-analyses. Psychological Bulletin, 143:6, 565-600. http://dx.doi.org/10.1037/bul0000098

Topping, K.J. (2009). Peer Assessment. Theory Into Practice. 48:1, 20-27. doi: $10.1080 / 00405840802577569$

von Müllen, R., Bechmann Jensen, T., Hansen, H. (2018). Feedback i Studenterperspektiv. Københavns Universitet. https://samf.ku.dk/pcs/feedbackrapport.pdf

Winstone, N.E., Nash,R.A., Rowntree, J., \& Parker,M. (2017). 'It'd be useful, but I wouldn't use it': barriers to university students' feedback seeking and recipience. Studies in Higher Education, 42:11, 2026-2041. DOI: 10.1080/03075079.2015.1130032.

\footnotetext{
'At disse mindre succesfulde forsøg ikke fylder mere i akademiske publikationer kan troligt skyldes publikationsbias.

ii I den engelsksprogede litteratur bruges langt oftere 'peer assessment', selv når praksissen ikke involverer bedømmelse.

iii Se Elbow (1981) for en beskrivelse af hhv. 'criterion-based' og 'reader-based feedback'.

iv Race (2013) giver anvisninger til en omhyggelig kriterieopbygningsproces. Reddy \& Andrade (2010) og Andrade (2005) forklarer og begrunder brugen af rubrics.

$\checkmark$ Eksempler er TEAMMATES, Peer Mark, My Reviewers eller det dansk udviklede Peergrade.io

vi Hattie \& Timperley (2007) uddyber denne definition af formålet med feedback og underinddeler feedbackens genstand i Opgaven (task), Processen, Selv-regulering og Selv.
} 